\title{
Educação Moral no Ensino Fundamental: Prática Docente de Ensino da Justiça
}

\author{
Leandra Lúcia Moraes Couto \\ Heloisa Moulin de Alencar \\ Universidade Federal do Espírito Santo \\ Vitória, ES, Brasil
}

\begin{abstract}
RESUMO
Trata-se de um estudo na área da Psicologia da moralidade e da educação moral. Objetivamos pesquisar os juízos de 23 docentes, 11 de $1^{\circ}$ e 12 de $5^{\mathrm{o}}$ ano do ensino fundamental, acerca do ensino da justiça. Além disso, propomosnos a verificar se tais práticas modificam-se em razão do ano escolar para o qual a participante leciona. Realizamos entrevistas semiestruturadas com base no método clínico piagetiano, bem como analisamos os dados de acordo com a referida teoria e a sistematização proposta por Delval. Constatamos que a maioria das práticas relatadas trata de meios que estão embasados em ações impositivas. Ademais, averiguamos diferenças entre os anos escolares pesquisados: as docentes de $5^{\mathrm{o}}$ ano mencionam mais procedimentos impositivos. De modo geral, verificamos que os procedimentos adotados pelas docentes podem não favorecer a efetivação das finalidades por elas almejadas. A partir dos dados obtidos, enfatizamos a necessidade de intervenções com a população pesquisada.
\end{abstract}

Palavras-chave: Educação moral; Justiça; Professores de ensino fundamental.

\section{ABSTRACT}

\section{Moral Education in Primary School: Teaching Practice on Justice Teaching}

This psychological study is focused on morality and moral education. We aimed to investigate the judgments of 23 teachers, 11 from the first and 12 from the fifth year of elementary school, in relation to justice teaching. Furthermore, we proposed to verify whether such practices are modified because of the school year the participant teaches. We conducted semi-structured interviews based on Piaget's clinical method and analyzed the data according to this theory and the systematization proposed by Delval. We found that most of the reported practices deal with means that are grounded in imposing actions. Moreover, we ascertained differences between the school years surveyed: the fifth year teachers mention more imposing procedures. Overall, we found that the procedures the teachers adopt may not encourage the achievement of the aims desired. Based on the data obtained, we emphasize the need for interventions involving the population surveyed.

Keywords: Moral education; Justice; Primary school teachers.

\section{RESUMEN}

\section{Educación Moral en la Educación Primaria: Enseñanza Práctica de la Enseñanza de la Justicia}

Se trata de un estudio de la psicología de la moral y la educación moral. El objetivo fue investigar los juicios de 23 profesores, 11 de $1^{\circ}$ y 12 de $5^{\circ}$ año de la enseñanza Elemental, acerca de la educación en justicia. Además, nos proponemos para verificar si tales prácticas se modifican debido a el año escolar en el cual el participante enseña. Realizamos entrevistas semiestructuradas con base en el método clínico de Piaget, y se analizaron los datos de acuerdo con esta teoría y la sistematización propuesta por Delval. Tomamos nota de que la mayoría de las prácticas reportadas llega a los medios que se basan en las acciones impositivo. Además, determinamos diferencias entre años escolares encuestados: los maestros año quinto mencionan más procedimientos imposiciones. En general, encontramos que los procedimientos adoptados por los maestros pueden no favorecer la efectivización de los propósitos para ellos almejadas. De los datos obtenidos, destacamos la necesidad de intervenciones a la población encuestada.

Palabras clave: Educación moral; Justicia; Maestros de escuela primaria. 


\section{INTRODUÇÃO}

Neste estudo, dedicamos-nos a investigar os juízos de professoras acerca do ensino do valor moral da justiça em suas práticas pedagógicas. Além disso, propomos-nos a verificar se tais práticas modificam-se em razão do ano escolar para o qual a participante leciona. Com base em Piaget (1932/1994), compreendemos que há um desenvolvimento da moralidade. Nesse sentido, os valores que compõem as representações de si dos indivíduos são construídos ao longo do processo de socialização.

Para Piaget (1932/1994), o desenvolvimento do juízo moral é caracterizado pela evolução de duas tendências morais, denominadas heteronomia e autonomia. De acordo com essa teoria, até os quatro anos de idade, aproximadamente, as crianças estão em uma fase de anomia. Após esse período, a moral começa a fazer parte do universo de valores das crianças e inicia-se a fase denominada heteronomia. A moral heterônoma é a moral do respeito unilateral, cuja fonte de legitimação das regras caracteriza-se pela referência à autoridade. Nela, a criança desenvolve o sentimento de obrigatoriedade, o qual corresponde a um mandamento de consciência que impele o indivíduo a agir de determinada maneira (La Taille, 2006; Piaget, 1932/1994). Por sua vez, em torno dos nove anos de idade, a criança pode apresentar sinais de autonomia. A moral autônoma é a moral da justiça, do respeito mútuo, em que prevalecem as relações de cooperação.

Vale dizer que, juntamente com La Taille (2006, 2010b), entendemos que a moral refere-se a leis, deveres que normatizam as condutas humanas. Os conteúdos do plano moral estão vinculados às possibilidades de resposta à pergunta "como devo agir?" (2006, p. 29). Por outro lado, a ética diz respeito a ideais, projetos que dão sentido à vida. À reflexão ética cabe a resposta à pergunta "que vida eu quero viver?" (p. 29). O plano moral é o lugar do sentimento de obrigatoriedade. Já o invariante psicológico do plano ético corresponde à busca de sentido para a vida, o qual possui outro invariante: o sentimento de expansão de si próprio.

Sobre os conteúdos dos planos moral e ético, eles podem ser os mais variados. Portanto, La Taille (2006) ressalta que "devemos definir conteúdos para a moral, pois é ela que confere às 'opções de vida boa' a sua legitimidade" (p. 60). O autor escolhe três virtudes morais: justiça, generosidade e honra. Com relação ao presente estudo, escolhemos estudar a justiça, que, para Piaget (1932/1994), é a mais racional das noções morais. Além disso, este conteúdo é preconizado pelos Parâmetros Curriculares Nacionais - PCNs - (Brasil, 2000) para ser trabalhado no ensino fundamental. Piaget
(1932/1994) realizou estudo pioneiro com relação ao desenvolvimento da noção de justiça. Segundo o autor, há duas noções distintas de justiça, denominadas distributiva e retributiva. A justiça distributiva define-se pela igualdade, ou seja, na noção de que uma repartição é injusta quando favorece uns à custa de outros. Nessa perspectiva, a justiça desenvolve-se a partir da aquisição da noção de igualdade e de equidade. Já a justiça retributiva define-se pela proporcionalidade entre $o$ ato e a sanção.

Isto posto, concordamos com Piaget (1930/1996, p. 3) quando afirma que não há "moral sem sua educação moral, 'educação' no sentido amplo do termo, que se sobrepõe à constituição inata do indivíduo". Segundo o aludido autor, o objetivo da educação moral é constituir indivíduos autônomos, aptos à cooperação.

Por sua vez, La Taille (2009) destaca que os responsáveis pela educação moral de crianças e de jovens devem empenhar-se para que as novas gerações penetrem numa cultura de sentido. Diante disso, o autor aponta algumas direções para que os adultos de forma geral, e aqueles envolvidos com instituições educacionais em específico, possam ajudar os jovens a construir a perspectiva ética. Assim, ele propõe que se promova a valorização da busca da verdade, do pensar bem, da boa fé. Indica, ainda, a preservação da memória, das referências ao passado, assim como destaca a necessidade de articulação entre conhecimento e sentido. De acordo com La Taille, a educação moral pressupõe o cuidar das crianças e dos jovens, fazendo-os crescer e desenvolver a autonomia. Já segundo Araújo (2000), a educação moral deve propiciar os instrumentos necessários para que os indivíduos construam sua competência cognitiva, afetiva, sociocultural e biofisiológica. Portanto, para este autor, a formação moral deve considerar e atuar sobre essas quatro dimensões constituintes da natureza humana.

Conforme Puig (2007), a finalidade da educação em valores é propiciar aprendizagens éticas, que inclua todas as facetas humanas, a saber: "aprender a ser", "aprender a conviver", "aprender a participar" e "aprender a habitar o mundo". "Aprender a ser" diz respeito a construir uma ética pessoal, o qual faça o indivíduo ser capaz de construir critérios próprios de conduta; reforce a vontade, a autorregulação e incremente a consciência de si mesmo. "Aprender a conviver" diz respeito à tarefa formativa para superar a tendência ao isolamento entre pessoas, ajudando os indivíduos a estabelecer vínculos pessoais baseados na compreensão do outro e no compromisso com projetos em comum. "Aprender a participar" é a aprendizagem da vida em comum, ou seja, é trabalhar por uma ética 
que torne os indivíduos cidadãos ativos. "Aprender a habitar o mundo" é a proposta de um trabalho educativo reflexivo sobre a responsabilidade pelo planeta.

Ainda com relação às finalidades da formação moral, há autores, como Araújo (2000) e Puig (2007), que enfatizam que as propostas de formação moral englobem os aspectos afetivos dos educandos. Além deles, outros autores, como D'Aurea-Tardeli (2012), concordam com essa necessidade. Tal proposta trata da possibilidade de que os alunos falem e reflitam sobre os próprios sentimentos e emoções. Por outro lado, La Taille (2009) vai de encontro à proposta de "educação sentimental", não indicando esta forma de educação para a moralidade. $\mathrm{O}$ autor alerta para o perigo que se corre quando obrigamos os jovens a abrirem a fronteira que protege a sua intimidade, a qual é necessária para o equilíbrio psicológico. Outro problema mencionado pelo referido autor diz respeito ao fato de obrigar o aluno a entrar em contato com aspectos emocionais e sentimentais de sua vida, sem oferecer apoio psicológico caso necessário. O autor questiona, ainda, a competência profissional que a escola e seus professores têm para lidar com tais aspectos da vida psíquica dos educandos. Em contrapartida, La Taille (2009) defende a ideia de que a educação moral pode procurar garantir a expressão e o desabrochar de determinados sentimentos morais, bem como buscar que os alunos reflitam sobre o valor humano desses sentimentos, o que, para ele, é diferente de refletir sobre os próprios sentimentos.

No que diz respeito aos procedimentos que podem ser adotados na formação moral dos alunos, a legislação brasileira e diferentes autores descrevem uma diversidade de meios. Sobre este aspecto, é importante ressaltar que dependendo de como é conduzida tal formação, ela determinará comportamentos de maneiras distintas (Piaget, 1930/1996). Dessa maneira, Piaget (1930/1996) discute que os procedimentos de educação moral podem ser classificados sob o ponto de vista dos fins perseguidos, das técnicas empregadas e do domínio moral considerado. Segundo o autor, a questão primordial reside em saber quais são as disponibilidades da criança.

Como vimos, para Piaget (1932/1994, 1930/1996), há duas tendências morais. De forma geral, a moral resultante das relações de coação e respeito unilateral conduz a um resultado específico que é o sentimento de dever. Por outro lado, aquela que resulta das relações de cooperação e respeito mútuo pode caracterizar-se por um sentimento mais interior à consciência, que é o sentimento de bem. Dessa maneira, de acordo com Piaget (1930/1996), um problema que se encontra no que concerne aos procedimentos de educação moral diz respeito ao fato de que, enquanto uns apelam somente para recursos do respeito unilateral, outros recorrem somente para a cooperação entre os indivíduos. Com relação a esta situação, o autor afirma: "o respeito mútuo é uma espécie de forma limite de equilíbrio para a qual tende o respeito unilateral, e pais e professores devem fazer de tudo o que for possível, segundo cremos, para converterem-se em colaboradores iguais à criança" (p.14). Para ele, essa possibilidade, no entanto, depende da própria criança, e durante os primeiros anos um elemento de autoridade inevitavelmente se mescla às relações que unem as crianças aos adultos. Assim, de acordo com este autor, o fundamental consiste em não negligenciar nem o respeito mútuo e nem o respeito unilateral, pois são fontes essenciais da vida moral.

Sobre este assunto, La Taille (2002) discute o fato de que uma vez que a heteronomia é anterior à autonomia, procede da posição piagetiana que o desenvolvimento da moralidade depende, em um momento inicial, de relações assimétricas, do exercício da autoridade por parte dos educadores. Sem tal relação, não se concebe que a criança entre no mundo moral. Além disso, o autor afirma que o que pode estar acontecendo na atualidade com determinadas crianças e jovens, é que eles não desenvolveram um senso moral. Tal quadro equivale à anomia. Nesse sentido, La Taille ressalta a importância de expor claramente aos jovens os valores e as regras que devem ser respeitados para que eles possam avaliá-las.

Por outro lado, é necessário considerar, também, conforme discute Tognetta e Vinha (2011), o excesso de regras que é estabelecido no contexto escolar. Segundo as autoras, muitas vezes a prática de elaboração de regras não é embasada em procedimentos que favorecem o desenvolvimento da autonomia. Para elas, são legitimadas práticas autoritárias, cujo enfoque está na resolução de conflito e não no processo pelo qual se chega à elaboração da regra. Além disso, conforme Tognetta e Vinha, nos regimentos escolares constam regras em que se misturam as convencionais, as morais, as unilaterais e as autoritárias. Dentre estas, as referidas autoras assinalam que há, também, aquelas que são desnecessárias. Diante disso, ressaltam que todo educador deve refletir "continuamente sobre os princípios que subjazem as normas, pois muitas vezes serão identificadas regras válidas e outras que visam apenas ao controle e à submissão" (p. 37). Na mesma linha, La Taille (2010a) adverte para o fato de que ao trabalhar os deveres morais com os alunos, maior importância deve ser dada à reflexão sobre os princípios que inspiram tais regras.

Retomando as teorizações de Piaget (1930/1996), quando tratamos das técnicas gerais de educação moral, 
restam analisar dois aspectos além daqueles referentes ao tipo de respeito ou relações interindividuais que as fundamentam, a saber: os procedimentos verbais e os métodos "ativos" de educação moral. Sobre os procedimentos verbais, o autor afirma que podemos distinguir um grande número de variações: do mais verbal ao mais "ativo", ou seja, do mais impregnado de coação adulta ao mais próximo da criança. Nos procedimentos verbais, estão incluídas as "lições morais", que são aquelas que se caracterizam por um programa sistemático de ensino de valores, em que é divulgado o que é considerado como verdade e a criança é coagida a recebê-la toda pronta. Há também as conversações morais, as quais se definem por relatos ou comentários a respeito de exemplos históricos ou literários. Ainda sobre os procedimentos verbais, Piaget descreve um terceiro tipo de método, que são aqueles que visam inserir a moral em todo o processo de educação. Neste caso, recorre-se ao ensino verbal somente nas ocasiões oferecidas pelas diversas disciplinas da grade curricular.

Piaget (1930/1996) destaca que todos os procedimentos orais descritos acima têm em comum o fato de suporem como única fonte de inspiração moral a autoridade do adulto em geral, ou a do professor em específico. Nesse sentido, assentam-se sempre sobre um fundo de respeito unilateral. Para o autor, ainda que o respeito mútuo passe a ser fonte da experiência moral, nem todos os elementos da discussão e transmissão oral devem ser proscritos. No entanto, afirma que a "lição de moral" deve ser a resposta a uma questão prévia.

No que concerne aos métodos "ativos", Piaget (1930/1996) descreve três pontos a serem assinalados. O primeiro deles diz respeito ao fato de que, na escola ativa, a educação moral não se constitui como uma matéria de ensino, mas um aspecto particular da totalidade do sistema. Assim, a vida moral deve estar intimamente ligada a toda atividade escolar. O segundo refere-se à importância da cooperação: a escola ativa pressupõe a colaboração no trabalho. Vale dizer também que, para o aludido autor, a cooperação é o procedimento mais fecundo de educação moral. O terceiro ponto trata dos procedimentos "ativos" especificamente morais, os quais são inspirados na noção de self-government, ou seja, na ideia de que não há método melhor para aprender acerca de determinado assunto do que descobrir por si só, por meio de uma experimentação verdadeira. Por fim, Piaget afirma que o método ativo busca sempre não impor pela autoridade o que a criança pode descobrir por si mesma, assim como procura criar um meio social no qual ela possa fazer as experiências desejadas. Para ele, os métodos ativos parecem superiores aos demais.
Isto posto, passamos a apresentar alguns procedimentos que podem ser utilizados na educação em valores morais. Começamos tratando do convívio escolar (Brasil, 2000; La Taille, 2009), isto é, a qualidade das relações sociais que são estabelecidas na escola, a qual exerce papel fundamental na educação em valores. Conforme os PCNs (Brasil, 2000, p. 121), "o convívio respeitoso na escola é a melhor experiência moral que o aluno pode viver". A ênfase deve estar em praticar, no dia a dia, as questões morais refletidas. Nesse sentido, as relações sociais no ambiente escolar devem ser pautadas no respeito mútuo, na justiça, entre outros valores. Assim, as atividades cooperativas ganham destaque na referida formação, pois constituem a base para a construção da autonomia (Piaget, 1930/1996; Puig, 2007).

Por sua vez, no que concerne ao diálogo, os PCNs (Brasil, 2000) indicam este procedimento como um dos conteúdos do Tema Transversal Ética. A proposta é que a escola ensine a capacidade de saber ouvir o outro e de se fazer entender, pois este é um dos principais instrumentos de uma sociedade democrática, em que há garantia de expressão de diversas ideias. Sobre este procedimento, é importante mencionar que, para García e Puig (2010), o diálogo, além de um método, é uma finalidade moral, pois os alunos não devem apenas dominá-lo, mas devem adquirir convicções sobre o seu valor e sobre como utilizá-lo.

A transversalidade é, também, um procedimento proposto na educação em valores morais (Brasil, 2000; La Taille, 2009; Puig, 1988). Tal procedimento caracteriza-se pela integração de temas (sociais e/ou morais) às áreas convencionais. De acordo com essa proposta, os referidos temas a serem trabalhados não devem ser abordados em uma disciplina específica. Ao contrário, devem ser contemplados por todos os docentes a partir dos conteúdos de suas matérias. Vale ressaltar que o conceito de transversalidade difere-se do conceito de interdisciplinaridade, pois o primeiro refere-se à possibilidade de inclusão de saberes extraescolares, e o segundo diz respeito a uma relação entre disciplinas (Brasil, 2000).

Embora se reconheça a relevância da transversalidade para a educação em valores morais dos alunos, tal formação pode acontecer, também, por meio de disciplinas específicas, como nas aulas de Filosofia e Ciências Humanas e disciplina de educação moral (La Taille, 2009). La Taille (2009) propõe que as referidas disciplinas sejam incluídas no currículo escolar a partir do ensino médio, pois, para refletir sobre textos filosóficos e científicos, é necessário que os alunos possuam capacidades de pensamento hipotéticodedutivo e motivação para discutir temas sociais. É importante mencionar que o mesmo autor ressalta que 
não se pode esperar até o ensino médio para ajudar os alunos a refletir sobre a moral. Assim, também devem ser pensados outros projetos de formação moral para os anos iniciais.

Conforme vimos, muitos podem ser os procedimentos utilizados na educação em valores morais. Dessa forma, autores (Araújo, 2000; Piaget, 1930/1996) ressaltam que este tipo de trabalho deve ter relação com situações práticas dos educandos. Conforme Araújo (2000), quando o educando não compreende a utilidade de determinado conteúdo para a sua vida, aumenta a probabilidade de apatia ou de manifestação de formas de violência.

Por último, consideramos relevante mencionar o estudo de Müller e Alencar (2012), no qual as autoras investigaram como professoras de $6^{\mathrm{O}}$ ao $9^{\mathrm{O}}$ ano do ensino fundamental ensinam a justiça em suas práticas pedagógicas. Dentre os resultados, foi constatado que a maioria dos exemplos citados pelas participantes caracteriza-se por ações com imposição.

Após a explicitação de conteúdos referentes à educação em valores morais, apresentamos, a seguir, o método utilizado em nosso estudo.

\section{MÉTODO}

Entrevistamos 23 professoras, divididas em dois grupos: 11 de $1^{\mathrm{O}}$ ano e 12 de $5^{\mathrm{O}}$ ano do ensino fundamental. Partindo da constatação de que todas as participantes consideram que ensinam a justiça, realizamos as seguintes indagações: como você ensina a justiça em suas práticas pedagógicas? Por que você ensina a justiça dessa forma? Nesse sentido, no presente trabalho analisamos os procedimentos de ensino da justiça relatados pelas participantes, bem como as justificativas para os meios mencionados. As entrevistas foram embasadas no método clínico piagetiano (Piaget, 1932/1994). Tal método caracterizase por uma intervenção sistemática do pesquisador frente à conduta dos participantes, com a finalidade de descobrir como estes pensam, analisam situações e resolvem problemas (Delval, 2002).

As participantes foram selecionadas por meio de contato com instituições públicas municipais, localizadas em bairros de classe baixa na cidade de Vitória, ES. A partir desse critério, obtivemos um total de 30 instituições. Por meio de um sorteio, elegemos a ordem dos colégios a serem contatados. Foi necessário visitar 10 instituições de ensino para compor o estudo. Resta dizer que todas as docentes que lecionavam para o $1^{\mathrm{O}}$ ou para o $5^{\mathrm{O}}$ ano nas escolas visitadas foram convidadas a participar da pesquisa. No entanto, nem todas aceitaram.
As entrevistas foram realizadas na escola que a participante trabalhava. Todas as entrevistas foram gravadas. Os dados foram analisados a partir da teoria piagetiana e da sistematização proposta por Delval (2002). Nesse sentido, com base na referida proposta, adotamos os seguintes passos na análise dos dados: a) transcrição de todas as entrevistas, b) leitura de todas as entrevistas, c) elaboração de categorias iniciais, d) discussão das categorias iniciais com duas auxiliares de pesquisa, e) elaboração de categorias detalhadas e resumidas e f) discussão com uma juíza para validação das categorias. Além disso, com relação às perguntas analisadas no presente artigo, realizamos o cruzamento das categorias resumidas dos procedimentos com as categorias resumidas das justificativas. Por fim, ressaltamos que, no decorrer do estudo, respeitamos os procedimentos éticos conforme prevê a Resolução no 196/1996 do Ministério da Saúde (1996).

\section{RESULTADOS E DISCUSSÃO}

$\mathrm{Na}$ questão a respeito de como as profissionais ensinam a justiça em suas práticas pedagógica, as participantes descreveram 131 procedimentos. Agrupamos o total de procedimentos mencionados em 15 categorias, sendo uma delas denominada outros $(\mathrm{n}=08)$, a qual contém conteúdos que não se adequaram aos demais grupos estabelecidos. É importante mencionar que, a partir das categorias resumidas elaboradas, classificamos os procedimentos mencionados em outras quatro categorias: verbal impositivo, verbal em geral, ação impositiva e ação em geral. Tais categorias são apresentadas e discutidas ao longo do texto.

Iniciamos com a apresentação e discussão dos procedimentos descritos. O discurso é o procedimento com maior frequência $(n=33)$. Nesta categoria, inserimos as respostas que fazem alusão ao uso da fala como meio para ensinar a justiça, isto é, referem-se à explicação, apresentação ou leitura de determinado tema pela docente, em que não há interlocução com os alunos. Por sua vez, averiguamos respostas que tratam da utilização de questionamento apontando o que é certo e errado $(\mathrm{n}=18)$, em que as entrevistadas lançam questionamentos aos alunos ao mesmo tempo em que ressaltam as próprias opiniões sobre o assunto.

Destacamos que as educadoras, ao descreverem os procedimentos discurso e questionamento apontando o que é certo e errado, muitas vezes não relatam a possibilidade de interlocução com os alunos. Quando mencionam, há prevalência de uma postura de imposição (categoria questionamento apontando o que é certo e errado), em que são feitos questionamentos 
sem o objetivo de obtenção de uma elaboração de resposta pelo aluno. Esses dois grupos de respostas chamam a atenção para a discussão realizada por Piaget (1930/1996) sobre o uso de lições e conversações morais como procedimentos de educação moral. Para ele, o ensino da moral pela palavra pode variar do mais impositivo ao mais "ativo".

Outro procedimento utilizado pelas docentes no ensino da justiça diz respeito à imposição verbal de regras $(\mathrm{n}=11)$. As participantes de $5^{\mathrm{o}}$ ano foram as que mais emitiram respostas incluídas nesta categoria $(n=9)$. Foram citadas regras como fazer silêncio no corredor, usar "palavrinhas mágicas" (falar "bom dia", "muito obrigado"), não mexer na bolsa do colega, não correr dentro de sala e limpar a sala de aula. Quanto à forma como essas regras são estabelecidas, com base nos discursos das entrevistadas, parece que elas são elaboradas a priori, sem a participação dos alunos. Dessa maneira, tal método não recorre à participação da criança na elaboração das regras para o convívio em comum. Portanto, verificamos que as docentes também tendem a ter uma atitude impositiva com relação à decisão pelas regras que devem ser seguidas, recorrendo ao respeito unilateral a sua aplicação.

Sobre o estabelecimento de regras no contexto escolar, Tognetta e Vinha (2011) alertam para o fato de que são legitimadas práticas autoritárias por trás de mecanismos aparentemente democráticos, como rodas de conversas. As autoras ressaltam a necessidade de se rever os regimentos de algumas escolas que querem educar para a autonomia. Para elas, nos referidos regimentos constam regras em que se misturam as convencionais e as morais, as unilaterais e as autoritárias, ou até mesmo aquelas desnecessárias.

Porém, vale mencionar que, conforme afirma Piaget (1930/1996), o respeito unilateral também é importante para o desenvolvimento da moralidade. Para o autor, a questão principal está em não negligenciar os dois tipos de respeito: mútuo e unilateral. Nessa perspectiva, os educadores devem proporcionar um ambiente favorável para que as regras desejáveis para o convívio em sociedade sejam discutidas e refletidas, tendo como base o diálogo e a participação ativa dos educandos. Além disso, como bem discute La Taille (2010a) e Tognetta e Vinha (2011), deve ser dada maior importância à reflexão sobre os princípios que inspiram as regras. Dessa forma, as regras passam a ter mais sentido e, na ausência das mesmas, os indivíduos saberão guiar-se por meio de princípios morais.

Vejamos, uma vez que a autonomia moral corresponde à superação da heteronomia (Piaget, 1932/ 1994), ocorre que, em um primeiro momento, o desenvolvimento da moralidade depende de relações assimétricas, do exercício da autoridade por parte dos educadores (La Taille, 2002). Sobre este fato, La Taille (2002) assinala, além de outros fatores, que o que pode estar acontecendo hoje com determinadas crianças e jovens, é que eles não desenvolveram um senso moral, não aceitam limites e recusam qualquer restrição de liberdade - quadro este que corresponde à anomia. Conforme este autor, tal situação pode ser decorrente da indecisão de vários adultos em relação ao que deve ser proibido e permitido, ao que é certo e errado. Desse modo, é necessário expor claramente os valores e as regras que devem ser respeitadas para que os alunos possam avaliá-las (La Taille, 2002).

Antes de continuarmos a discussão dos dados, é importante assinalar uma característica das categorias que acabamos de discutir: discurso, questionamento apontando o que é certo e errado e imposição verbal de regras. Elas tratam de procedimentos que podemos denominar de verbal impositivo. Além dos grupos citados, verificamos, ainda, uma resposta na categoria outros, em que a participante afirma que ensina a justiça chamando a atenção com questionamentos, fazendo, portanto, alusão ao meio verbal impositivo. Assim, somando essas respostas, obtemos 63 explanações que tratam de métodos embasados na linguagem e com caráter impositivo.

Dando sequência à análise dos procedimentos, constatamos respostas que versam sobre o questionamento $(\mathrm{n}=13)$. Nesta categoria, agrupamos as práticas em que as docentes fazem questionamentos aos alunos sem, no entanto, emitir uma resposta para tal problematização, isto é, suas concepções sobre o que é certo e errado. As aludidas práticas aproximam-se do convite ao aluno à argumentação, ao diálogo. A respeito do diálogo, encontramos na legislação brasileira (Brasil, 2000) e em alguns autores (García \& Puig, 2010; Piaget, 1932/1994, 1930/1996; Puig, 1998, 2007) a preconização deste procedimento como um meio valioso para a formação moral dos indivíduos. Diante disso, García e Puig (2010) descrevem atividades para ajudar os professores a desenvolverem capacidades e a tornarem-se facilitadores do diálogo.

Por sua vez, averiguamos a categoria conversa em geral $(\mathrm{n}=08)$, que diz respeito às práticas que as docentes denominaram como conversa, mas que não conseguimos identificar o teor desta: com ou sem questionamentos, dentre outros aspectos. Vale dizer que inserimos nas categorias discurso, questionamento apontando o que é certo e errado, questionamento e conversa em geral todas as explanações que contemplam o conteúdo aludido, mesmo quando a participante utilizou outro termo para descrever a sua prática. A referida indiferenciação dos conceitos 
também foi verificada no estudo de Müller e Alencar (2012).

A inserção verbal no conteúdo da disciplina $(\mathrm{n}=08)$ é outro procedimento adotado pelas participantes. Como exposto, a educação em valores morais no contexto escolar pode ser implantada por meio de disciplina específica (La Taille, 2009), bem como de forma transversal (Brasil, 2000; La Taille, 2009; Puig, 1998). Com relação ao nosso estudo, as docentes afirmaram que ensinam a justiça a partir dos conteúdos de suas próprias matérias, favorecendo, com isso, a realização da transversalidade. Porém, para que tal método seja realmente posto em prática, a formação moral deve ser vista como parte de todo o processo educativo e deve ser estabelecida uma política pedagógica escolar visando a tal fim.

Obtivemos, ainda, um pequeno número de respostas sobre o trabalho interdisciplinar $(\mathrm{n}=02)$, ou seja, a justiça é ensinada juntamente com profissionais de outras disciplinas, e acerca do levantamento de informações $(\mathrm{n}=02)$, no qual se busca obter dados a respeito dos alunos e das famílias dos educandos.

Assim, cinco categorias obtidas fazem alusão a procedimentos que podemos intitular como verbal em geral, pois a linguagem é utilizada como meio e não foi mencionado o uso de imposição. São elas: questionamento, conversa em geral, inserção verbal no conteúdo da disciplina, trabalho interdisciplinar e levantamento de informações. Além destas, encontramos uma resposta na categoria outros que versa sobre a análise do que é certo e errado. Assim, dos 131 procedimentos relatados, averiguamos 34 explanações com este teor.

Prosseguindo a discussão dos dados, constatamos respostas que tratam da punição $(\mathrm{n}=15)$ como forma de ensino da justiça. Foram mencionadas punições como privar o aluno da aula de educação física, privar da aula de informática, privar do recreio, mandar abrir a bolsa e colocar o aluno sentado ao lado da mesa do professor. Com relação à justiça retributiva, Piaget (1932/1994) descreve dois tipos de sanções: expiatórias e por reciprocidade. Nesse sentido, para o autor, nem sempre uma punição será considerada justa. Portanto, alertamos para as punições que são realizadas no ambiente escolar, uma vez que estas podem ser caracterizadas como situações injustas, não favorecendo o ensino da justiça. Vale dizer que no estudo de Müller e Alencar (2012) também foi averiguada a punição como prática de ensino da justiça. Tal dado reforça o que acabamos de discutir.

As entrevistadas explanaram, ainda, que ensinam a justiça por meio de uma ação impositiva para resolver problema $(\mathrm{n}=02)$. As ações citadas foram as seguintes: intervenção impositiva em um conflito entre os alunos envolvendo partilha de alimento e encaminhamento de um aluno para a coordenação escolar. Dessa maneira, a punição e a ação impositiva para resolver problema são procedimentos que podem ser classificados como ação impositiva das docentes. Os referidos procedimentos somam 17 respostas.

Voltando aos dados, temos a categoria própria atitude de forma geral $(\mathrm{n}=04)$. Este grupo de respostas contém explanações que tratam do comportamento da professora de forma geral, uma vez que elas afirmaram que ensinam a justiça dando o próprio exemplo, sendo justas nas ações, sem apontar em qual situação particular. Por outro lado, estabelecemos a categoria ação especifica para resolver problema $(\mathrm{n}=02)$, na qual englobamos os depoimentos que dizem respeito a uma ação específica da docente, realizada a fim de solucionar um problema. As práticas inseridas neste grupo versam sobre a providência de material escolar quando falta para algum aluno e a reposição de avaliação.

Por sua vez, as docentes também afirmaram que ensinam a justiça por meio do lúdico $(\mathrm{n}=03)$, de forma geral ou com brincadeiras, bem como do afeto/carinho $(\mathrm{n}=02)$, acarinhando o aluno. Assim, analisando as quatro últimas categorias descritas, podemos notar que as respostas fazem referência a uma ação das professoras em que não é mencionada a utilização de imposição. Portanto, podemos denominar tais práticas como ação em geral. As aludidas categorias são: própria atitude de forma geral, ação especifica para resolver problema, lúdico e afeto/carinho. Também encontramos seis relatos com este conteúdo na categoria outros, os quais envolvem partilha de livro ou jogo em sala de aula, busca de parceria com a família, busca de parceria com a escola, passeio, escuta do que os alunos trazem para a sala de aula e respeito nas relações. Logo, totalizam 17 respostas.

Isso posto, assinalamos que do total de procedimentos descritos pelas entrevistadas $(n=131), 80$ deles são meios com a utilização da imposição: verbal impositivo e ação impositiva. Por outro lado, em 51 métodos não é mencionado o uso da imposição: verbal em geral e ação em geral. Além disso, grande parte dos procedimentos é embasada exclusivamente na linguagem oral, sem a realização de alguma ação por parte da docente. Somando os meios que denominamos de verbal impositivo e verbal em geral, obtemos um total de 97 explanações.

Quanto à utilização de imposição como meio para o ensino da justiça, podemos verificar dados semelhantes aos nossos no estudo de Müller e Alencar (2012). As autoras constataram que 21 práticas de 
ensino da justiça relatadas pelas docentes entrevistadas têm como base ações com imposição. Por sua vez, o "diálogo" foi averiguado em nove respostas. As ações impositivas não estimulam um avanço moral. Assim, tais condutas devem ser substituídas por aquelas em que há o estímulo ao diálogo, à descentração.

Ainda com relação a este tópico, verificamos que as participantes de 5o ano tendem a utilizar mais procedimentos com base em práticas com caráter impositivo do que as entrevistadas de $1^{\circ} \stackrel{\mathrm{O}}{ }$ ano. Estas, por sua vez, utilizam mais procedimentos nos quais não foi mencionada a imposição. No que concerne aos métodos classificados como verbal impositivo e ação impositiva, as docentes de $5^{\circ}$ ano totalizam 47 respostas, enquanto aquelas de $1^{\circ}$ ano somam 33 explanações. Sobre os meios denominados como verbal em geral e ação em geral, as participantes de $1^{\mathrm{O}}$ ano emitiram um total de 33 citações e as de 5ำ ano 18 menções.

Com base no que foi exposto, questionamos se os procedimentos utilizados pelas docentes no ensino da justiça aproximam-se do que Piaget (1930/1996) denomina de métodos "ativos" de educação moral. Para tentarmos responder a tal indagação, precisamos conhecer as justificativas emitidas pelas docentes para os meios adotados em suas práticas. Passamos, então, à apresentação das justificativas obtidas, um total de 99 explicações, as quais foram agrupadas em 14 categorias. Também nesta questão, estabelecemos a categoria outros $(\mathrm{n}=22)$. Vale ressaltar que os dados apresentados a seguir foram analisamos com base no cruzamento entre as respostas e as justificativas obtidas em nosso estudo. Destacamos, também, que analisamos as categorias resumidas de justificativas com relação aos seus embasamentos: foco no aluno, foco no professor, foco na relação entre professor e aluno, foco na grade curricular e foco na família. Essa análise é realizada no decorrer da discussão dos dados.

A reflexão proporcionada ao aluno $(\mathrm{n}=15)$ é o argumento mais empregado para justificar as práticas de ensino da justiça. Do total de explicações incluídas neste grupo, nove foram emitidas para justificar procedimentos classificados como verbal impositivo, quatro para aqueles denominados como ação impositiva e dois para os intitulados como verbal em geral. Diante disso, constatamos que as participantes utilizam este motivo, em grande número, para fundamentar o uso de procedimentos que, conforme expomos, estão embasados em práticas impositivas. Logo, podem não favorecer a reflexão. Juntamente com alguns autores (García \& Puig, 2010; Piaget, 1932/1994, 1930/1996; Puig, 1998, 2007) defendemos o diálogo como meio favorável à formação moral dos alunos.
Em seguida, temos a justificativa necessidade de compreensão das consequências dos atos $(\mathrm{n}=09)$, que trata da necessidade de agir de determinada forma para que os alunos compreendam que suas atitudes geram consequências. Verificamos que este motivo foi emitido em sua totalidade para justificar procedimentos classificados como ação impositiva.

Constatamos que as entrevistadas também explicam suas práticas pela possibilidade de desenvolver sujeitos criticos ou participativos $(\mathrm{n}=09)$. As participantes relataram este argumento para justificar procedimentos denominados como verbal em geral $(n=6)$ e verbal impositivo $(\mathrm{n}=3)$. Esta explicação denota que as entrevistadas utilizam os referidos procedimentos devido à consideração de que eles favorecem a aprendizagem ética "aprender a participar" (Puig, 2007). Podemos questionar, entretanto, se os procedimentos adotados pelas entrevistadas são os mais indicados para favorecer a referida aprendizagem. Por um lado, notamos que algumas participantes utilizam procedimentos que podem beneficiar tal aprendizagem (verbal em geral). Por outro, há aquelas que fazem uso de meios que podem não propiciar o mesmo resultado (verbal impositivo).

Por sua vez, averiguamos o grupo de justificativas acerca do incentivo ao aluno $(\mathrm{n}=08)$. Foram emitidas explicações como o incentivo ao aluno a deixar de ser violento. Essas explicações foram emitidas para justificar o uso de métodos classificados como verbal impositivo $(\mathrm{n}=5)$ e ação em geral $(\mathrm{n}=3)$. Conforme podemos notar, aqui encontramos práticas impositivas pelas quais se busca incentivar os educandos.

Outra justificativa relatada diz respeito à aprendizagem ser facilitada $(\mathrm{n}=07)$ : pelo concreto $(n=2)$, de forma geral $(n=2)$, dentre outras formas $(n=3)$. Tal fundamento foi abordado como motivo para a utilização de meios intitulados como verbal impositivo $(\mathrm{n}=5)$, verbal em geral $(\mathrm{n}=1)$ e ação em geral $(\mathrm{n}=1)$. Assim, aqui também verificamos o uso de procedimentos impositivos com o objetivo de facilitar a aprendizagem dos alunos.

Por sua vez, as entrevistadas justificam os procedimentos utilizados pela possibilidade de expressão dos pensamentos ou sentimentos dos alunos $(\mathrm{n}=06)$. As professoras utilizam este fundamento para explicar o uso de meios denominados como verbal em geral $(n=6)$. Além disso, este tópico levanta uma questão acerca do papel da afetividade no que diz respeito à educação em valores morais. Há autores (D’AureaTardeli, 2012; Puig, 1998, 2007) que defendem a importância da inserção de temáticas relacionadas à afetividade no currículo escolar. Por outro lado, La Taille (2009) adverte para os perigos que tal empreitada 
pode acarretar. Assim, frente à complexidade do tema, questionamos se os profissionais da educação, em particular os professores, estão preparados para utilizar procedimentos visando o trabalho com a expressão dos sentimentos dos educandos.

Além dos argumentos analisados, as professoras justificam os procedimentos adotados pela pouca idade do aluno $(\mathrm{n}=04)$. Constatamos, assim, que as docentes têm a preocupação em adequar suas práticas de ensino da justiça à etapa do desenvolvimento em que as crianças encontram-se. No entanto, não é possível afirmar que as docentes, no momento da realização da entrevista, tinham conhecimento acerca das características que envolvem o desenvolvimento dos educandos (Piaget, 1932/1994). Ademais, do total de respostas inseridas nesta categoria, três foram relatadas para justificar métodos denominados como ação em geral e uma como verbal impositivo.

Obtivemos, também, a justificativa necessidade ou característica da turma $(\mathrm{n}=04)$, na qual agrupamos justificativas que versam sobre a escolha do procedimento de trabalho como decorrência de uma demanda apresentada pelos alunos. Foram descritas necessidades de forma geral, bem como a necessidade específica de carinho, entre outras. Este motivo foi relatado para justificar métodos classificados como verbal em geral $(\mathrm{n}=2)$ e ação em geral $(\mathrm{n}=2)$. Tais dados mostram que as participantes buscam utilizar procedimentos visando à relação de suas práticas com a vivência pessoal dos alunos. Conforme discutimos, esta conduta é aconselhada por autores como Araújo (2000) e Piaget (1930/1996).

Verificamos, ainda, com pouca frequência, a justificativa ausência de consequência negativa para o aluno $(\mathrm{n}=02)$. Foram incluídos argumentos acerca da possibilidade de não causar um dano para o aluno. Este tipo de motivo foi utilizado para procedimentos definidos como ação impositiva $(\mathrm{n}=1)$ e ação em geral $(n=1)$.

Antes de avançarmos na análise das justificativas, enfatizamos que os referidos grupos de justificativas descritos acima têm como foco o aluno, isto é, tratam de práticas que possuem como embasamento os educandos. São elas: a) reflexão proporcionada ao aluno, b) necessidade de compreensão das consequências dos atos, c) possibilidade de desenvolver sujeitos críticos ou participativos, d) incentivo ao aluno, e) aprendizagem ser facilitada, f) possibilidade de expressão dos pensamentos ou sentimentos, g) pouca idade do aluno, h) necessidade ou característica da turma e i) ausência de consequência negativa para o aluno. Além destas, na categoria outros encontramos
13 justificativas com este enfoque. Assim, juntos esses dados somam 77 justificativas.

Retomando a discussão das justificativas, averiguamos que a experiência pessoal ou profissional da participante $(\mathrm{n}=05)$ também serviu de base para fundamentar as práticas das docentes. Este argumento foi emitido para procedimentos denominados como verbal impositivo $(\mathrm{n}=2)$, verbal em geral $(\mathrm{n}=2)$ e ação em geral $(\mathrm{n}=1)$. Com base nessas justificativas, notamos que a escolha desses meios ocorre em consequência da experiência da participante, e que não há menção a autores da área da Psicologia da Moralidade e da Educação em valores morais, como Piaget (1930/1996), La Taille (2009), dentre outros. Apesar de reconhecermos a relevância do conhecimento que é adquirido mediante o exercício das práticas pedagógicas, consideramos que a formação e a preparação profissional para o desenvolvimento da educação em valores morais é imprescindível.

Ainda sobre este tópico, podemos perceber que esse é um tipo de justificativa com foco no professor. Com outras palavras, determinado método é adotado pela participante devido ao fato de ele visar ao próprio professor. Também encontramos na categoria outros sete explicações com esse foco. Com isso, totalizam 12 justificativas.

Voltando aos dados, temos a justificativa eficácia nas relações entre professor e aluno $(\mathrm{n}=03)$. No aludido grupo, incluímos as explicações nas quais as participantes fundamentam o procedimento utilizado pela promoção de um melhor entendimento entre professor e aluno, como, por exemplo, a obtenção de harmonia e paz no ambiente de trabalho. Por meio de uma análise mais detalhada, verificamos que essas professoras buscam tal eficácia ensinando a justiça por meio de procedimentos intitulados como verbal impositivo, ou seja, com base em ações impositivas. Portanto, tais práticas podem acarretar o prejuízo das relações interpessoais, e não a sua eficácia. O convívio escolar exerce papel fundamental no que concerne à educação em valores morais (La Taille, 2009; Brasil, 2000). Nesse sentido, as relações sociais no ambiente escolar devem ser pautadas na cooperação, no respeito mútuo, no diálogo, na justiça, na solidariedade, entre outros valores.

Além da justificativa eficácia nas relações entre professor e aluno, encontramos, na categoria outros, uma explicação cujo foco da justificativa também está nas relações entre professor e aluno. Assim, constatamos quatro justificativas sobre o referido foco.

Sobre os demais dados, houve um número menor de justificativas que fazem alusão à especificidade da grade curricular $(\mathrm{n}=03)$. Foram mencionados 
os seguintes aspectos: rompimento da fragmentação do conhecimento, necessidade de introduzir este tema também no primeiro seguimento e exigência de cumprimento de um conteúdo estipulado. Esta justificativa foi mencionada para procedimentos intitulados como verbal em geral $(\mathrm{n}=3)$. Resta dizer que, conforme podemos verificar, esse tipo de explicação possui como foco a grade curricular. Com base na perspectiva teórica adotada em nosso estudo, partimos do pressuposto de que há um desenvolvimento da moralidade, cujo despertar ocorre por volta dos quatro anos de idade (Piaget, 1932/1994). Diante disso, consideramos que a escola não pode esperar até o ensino médio para ajudar os alunos a refletir sobre a moral (La Taille, 2009). Diante disso, destacamos a necessidade de que sejam pensados projetos de formação moral também para os anos iniciais.

Por fim, verificamos, com pouca frequência, justificativas a respeito da ausência de participação da familia $(\mathrm{n}=02)$. As docentes fundamentam suas práticas com base na necessidade de utilizar determinado método, uma vez que a família não o faz. Tal motivo foi abordado para procedimentos classificados como verbal impositivo $(n=1)$ e verbal em geral $(n=1)$. Como podemos notar, essa categoria possui a família como embasamento para as práticas de ensino da justiça. Além desta, obtivemos uma justificativa com esse foco na categoria outros. Portanto, somam três argumentos com este teor.

Após a exposição dos procedimentos utilizados pelas professoras e das justificativas para tais práticas, podemos retomar nossa pergunta: os procedimentos de ensino da justiça relatados pelas participantes aproximam-se ou não dos métodos "ativos" de educação moral (Piaget, 1930/1996)? Vale lembrar que Piaget descreve, além dos procedimentos verbais de educação moral, os procedimentos ativos. Nessa perspectiva, um método ativo de educação em valores morais é aquele que favorece a criação de um meio social propício para que as crianças possam fazer as experiências desejadas. No que diz respeito aos nossos dados, verificamos práticas que podem promover este tipo de método, que são aquelas que possuem como foco os alunos. No entanto, será que as participantes de nossa pesquisa utilizam os procedimentos que favorecem o alcance de tal objetivo?

Conforme discutido, a maioria dos procedimentos utilizados pelas docentes possui ênfase no aluno. Assim, como o foco é o próprio aluno, as práticas realizadas deveriam ser aquelas que possibilitam um método "ativo" (Piaget, 1930/1996). No entanto, quando analisamos os métodos empregados pelas entrevistadas, que possuem o referido foco em suas justificativas, constatamos que a maior parte deles diz respeito a meios com o uso da imposição $(n=45)$. Assim, não favorecem os procedimentos ditos ativos e, provavelmente, o desenvolvimento moral dos educandos. Por outro lado, é importante considerar as menções de procedimentos em que não foi relatado o uso da imposição $(n=32)$, pois tais métodos podem ser empregados de modo a favorecer os métodos "ativos" (Piaget, 1930/1996).

Com relação às diferenças entre os anos escolares investigados, verificamos que as docentes de $1^{\mathrm{O}}$ ano emitiram mais justificativas com foco no aluno $(n=43)$ do que as participantes de $5^{\circ}$ ano $(n=34)$.

\section{CONSIDERAÇÕES FINAIS}

De modo geral, grande parte dos procedimentos adotados pelas docentes pode não favorecer a efetivação das finalidades por elas almejadas com o uso deles, uma vez que diz respeito a práticas que fazem uso de imposição no ensino da justiça. Além disso, a maioria dos procedimentos possui como foco o aluno, ou seja, são métodos que podem propiciar a participação ativa (Piaget, 1930/1996) dos educandos, bem como possibilitar a expansão de si dos mesmos (La Taille, 2006). No entanto, como mencionado, os meios utilizados podem não contribuir para o alcance de tais finalidades. Assim, chamamos a atenção para a necessidade de que as práticas de ensino da justiça sejam orientadas com base em autores da Psicologia da Moralidade e da Educação em valores morais, pois, como discute Puig (1998), a formação moral exige estratégias próprias. Ressaltamos, ainda, que as práticas impositivas podem contribuir para que os alunos permaneçam na heteronomia (Piaget, 1932/1994, 1930/1996).

Com relação às diferenças entre os anos escolares pesquisados, podemos fazer a seguinte indagação: por que as docentes de $5^{\circ}$ ano mencionaram mais procedimentos impositivos? Dentre outros fatores, ponderamos que os alunos de $5^{\mathrm{O}}$ ano podem estar apresentando comportamentos que trazem conflitos ao contexto escolar com maior frequência do que aqueles de $1^{\circ}$ ano, o que destaca a importância de projetos contínuos de educação em valores morais. Assim, chamamos a atenção para o fato de que a autonomia moral corresponde à superação da heteronomia (Piaget, 1932/1994). Nesse sentido, ambos os respeitos, unilateral e mútuo, são imprescindíveis para o desenvolvimento da moralidade. Em resumo, assinalamos que as relações assimétricas são inevitáveis e necessárias em determinados momentos. $\mathrm{O}$ 
importante é considerar, sobretudo, as possibilidades da criança, isto é, o período de desenvolvimento cognitivo e moral dos alunos.

Com os dados apresentados, esperamos contribuir para a melhoria da qualidade da educação em valores morais no contexto escolar, auxiliando possíveis intervenções nas práticas pedagógicas dos profissionais em pauta. Ressaltamos, porém, que nosso estudo possui limitações, dentre elas o número reduzido de participantes. Assim, destacamos a necessidade de realização de novas pesquisas, as quais possam investigar a preparação de professores para trabalhar com a expressão dos sentimentos dos educandos em sala de aula, o conceito de diálogo dos professores, a existência de traços de uma moral heterônoma na forma como tais profissionais ensinam a justiça, bem como o ensino desse valor moral nos demais anos iniciais do ensino fundamental.

\section{REFERÊNCIAS}

Araújo, U. F. (2000). Escola, democracia e a construção de personalidades morais. Educação e Pesquisa, 26(2), 91-107. http://dx.doi.org/10.1590/S1517-97022000000200007

Brasil. (2000). Parâmetros Curriculares Nacionais. Apresentação dos Temas Transversais: Ética. Secretaria de Educação Fundamental (2 ${ }^{\mathrm{a}}$ ed.) (Vol. 08). Rio de Janeiro: DP\&A.

D’Aurea-Tardeli, D. (2012). Outros procedimentos para educar moralmente: Como as histórias e a discussão de filmes podem ajudar na formação moral de nossos alunos? In L. R. P. Tognetta \& T. P. Vinha (Org.), É possível superar a violência na escola? Construindo caminhos pela formação moral (pp. 116-137). São Paulo: Editora do Brasil.

Delval, J. (2002). Introdução à prática do método clínico: Descobrindo o pensamento das crianças (F. Murad, trad.). Porto Alegre: Artmed.

García, M. X. \& Puig, J. M. (2010). As sete competências básicas para educar em valores (O. Curros, trad.). São Paulo: Summus.

La Taille, Y. (2002). Uma interpretação psicológica dos limites do domínio moral: Os sentidos da restrição e da superação. Educar, (19), 23-38. Recuperado de http://ojs.c3sl.ufpr.br/ojs2/index.php/educar/article/view/2079/1731 http://dx.doi.org/10.1590/0104-4060.244

La Taille, Y. (2006). Moral e ética: Dimensões intelectuais e afetivas. Porto Alegre: Artmed.

La Taille, Y. (2009). Formação ética: Do tédio ao respeito de si. Porto Alegre: Artmed.

La Taille, Y. (2010a). A escola e os valores: A ação do professor. In Y. La Taille, N. Pedro-Silva, \& Justo, J. S. Indisciplina/ disciplina: ética, moral e ação do professor (3ำ ed.) (pp. 5-21). Porto Alegre: Mediação.

La Taille, Y. (2010b). Moral e ética: Uma leitura psicológica. Psicologia: Teoria e Pesquisa (UnB. Impresso), 26(especial), 105-114. http://dx.doi.org/10.1590/S0102-37722010000500009

Ministério da Saúde (1996). Resolução 196/96, de 10 de outubro de 1996. Aprova as diretrizes e normas regulamentadoras de pesquisas envolvendo seres humanos. Brasília. Recuperado de www.conselho.saude.gov.br/

Müller, A. \& Alencar, H. M. (2012). Educação moral: O aprender e o ensinar sobre justiça na escola. Educação e Pesquisa (USP. Impresso), São Paulo, 38(2), 453-468. http://dx.doi.org/10.1590/S1517-97022012000200012

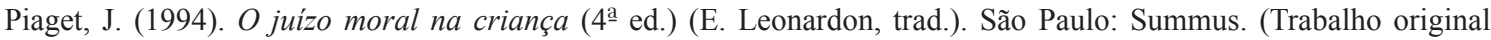
publicado em 1932).

Piaget, J. (1996). Os procedimentos da educação moral. In L. Macedo (Org.). Cinco estudos de educação moral (pp. 1-36). São Paulo: Casa do Psicólogo. (Trabalho original publicado em 1930).

Puig, J. M. (1998). Ética e valores: Métodos para um ensino transversal. (A. V. Fuzatto, trad.). São Paulo: Casa do Psicólogo.

Puig, J. M. (2007). Aprender a viver. In V. A. Arantes (Org.), Educação e valores: pontos e contrapontos (pp. 65-106). São Paulo: Summus.

Tognetta, L. R. P. \& Vinha, T. P. (2011). Quando a escola é democrática: um olhar sobre a prática das regras e assembleias na escola (2 $2^{\mathrm{a}}$ ed.). Campinas: Mercado de Letras.

\footnotetext{
Autores: Espírito Santo. Espírito Santo.

Endereço para correspondência:

Leandra Lúcia Moraes Couto

Departamento de Psicologia Social e do Desenvolvimento/Ufes

Av. Fernando Ferrari, 514 - Campus Universitário de Goiabeiras, CEMUNI VI

29075910 Vitória, ES, Brasil

Recebido em: 11.04.14

Aceito em: 15.08 .14
}

LeAndra Lúcia Moraes Couto - Doutoranda em Psicologia pelo Programa de Pós-Graduação em Psicologia da Universidade Federal do

Heloisa Moulin de AlencAR - Doutora em Psicologia e docente do Programa de Pós-Graduação em Psicologia da Universidade Federal do 